\title{
Multi-Layer Perceptron Neural Network and Markov Chain Based Geospatial Analysis of Land Use and Land Cover Change
}

\author{
L. Shen ${ }^{1}$, J. B. Li ${ }^{1}{ }^{*}$, R. Wheate ${ }^{2}$ J. Yin ${ }^{3}$, and S. S. Paul ${ }^{4}$ \\ ${ }^{I}$ Environmental Engineering Program, University of Northern British Columbia, Prince George, BC V2N 4Z9, Canada. \\ ${ }^{2}$ Geography Program, University of Northern British Columbia, Prince George, BC V2L 1R5, Canada. \\ ${ }^{3}$ Ministry of Forests, Lands, Natural Resources Operations \& Rural Development, Prince George, BC V2N 4W5, Canada. \\ ${ }^{4}$ Faculty of Land and Food Systems, University of British Columbia, Vancouver, BC V6T 1Z4, Canada.
}

Received 2 March 2020; revised 16 March 2020; accepted 24 March 2020; published online 31 March 2020

\begin{abstract}
We combined multi-layer perceptron (MLP) neural network and Markov Chain (MC) modeling with object-based image analysis (OBIA) to map and predict land use and land cover (LULC) changes in Stoney Creek Watershed (SCW), British Columbia, Canada. Unsupervised classification was performed using Landsat Thematic Mapper (TM) and Operational Land Imager (OLI) images to produce LULC maps of years 1986, 1999 and 2016. The classification resulted in an overall accuracy of $91.50 \%$. The results show that coniferous forest in SCW experienced a sharp loss while agriculture area increased (4.77\% land gain) from 1986 to 2016. LULC scenarios were predicted through MLP neural network and MC modeling based on LULC change analysis data and transition potential. The results indicated that 'Coniferous Forest' LULC type had the highest (3.38\% land loss) transition potential and 'Water' and 'Urban Area' LULC types had the lowest transition potential. Application of the proposed method provided valuable information of LULC patterns and dynamics for planners and researchers. The method also has the potential for improved management in other watersheds with similar LULC types.
\end{abstract}

Keywords: geospatial analysis, land use and land cover (LULC) change, landsat imagery, markov Chain (MC) model, multi-layer perceptron (MLP) neural network, object-based image analysis (OBIA).

\section{Introduction}

Land use and land cover are two different terms but are often used interchangeably by many researchers. Land use refers to the human use of the natural landscape for habitat and livelihood, while land cover represents the biophysical characteristics such as vegetation, soil and water distributed on earth's surface. The conversion of land use in the human subsystem driven by social activities will change land cover, and land cover changes could impact natural environment and biosphere (Rawat and Kumar, 2015; Islam, 2018a; Chen et al., 2018). As a result, land use and land cover (LULC) change resulting from anthropogenic activities has led to various concerns for environmental degradation around the globe (Islam et al., 2018b; Paul et al., 2018). The assessment of LULC change is thus of critical importance for effective environmental management and sustainable development of land resources.

Remote Sensing (RS) techniques can be used for LULC change detection and understanding the dynamics of the change. Due to the spatial data management, creation, and analysis func-

\footnotetext{
* Corresponding author. Tel.: +1-250-9606397; fax: +1-250-9605845. E-mail address: Jianbing.Li@unbc.ca (J.B. Li).

ISSN: 2663-6859 print/2663-6867 online

(C) 2020 ISEIS All rights reserved. doi:10.3808/jeil.202000023.
}

tions of geographic information systems (GIS), the combination of RS and GIS has been successfully applied as an effective technique in LULC change detection (Paul, 2013; Srivastava et al., 2013; Nguyen et al., 2016). Satellite remote sensing technology is especially popular as it is supported by satellite sensors which could provide time-series image data with high spatial resolution and geometric precision, and can capture temporal variation (Stabile, 2012; Pervaiz et al., 2016). Landsat satellite images which provide a continuous inventory of imagery since 1972 have been widely applied for LULC analysis (USGS, 2016). The Landsat sensors have proved sensitive enough to categorize different spectral patterns related to the LULC classes in many complex landscape conditions (Zhao et al., 2012; Butt et al., 2015). RS analysis for change detection is usually relying on digital satellite image classification by assigning image pixels to real-world LULC feature types (Paul et al., 2018). Pixel-based classification (PBC) is a conventional method and has been broadly applied as supervised and unsupervised classification based on characteristics of single pixel (MacLean et al., 2013; Rwanga and Ndambuki, 2017). However, when a pixel-by-pixel classification algorithm is applied to all available image signals, the pixels with similar spectral reflectance are grouped together, while some spatial and contextual information of image pixels are neglected. Thus, the pixels may not represent true geographical objects when using PBC method, and its accuracy would be affected (MacLean et 
al., 2013; Blaschke et al., 2014). Compared with PBC, the object-based image analysis (OBIA) method generates segments from pixel-based features to produce higher classification accuracy by incorporating more information and cre-ating more recognizable segments (Frohn, 2011; Chen et al., 2013; Ma et al., 2017; Paul et al., 2018). The OBIA method also allows more types of features in the image to be exploited for classification, and it can reduce the changes resulting from the occurrence of small and spurious pixels (Toure et al., 2018).

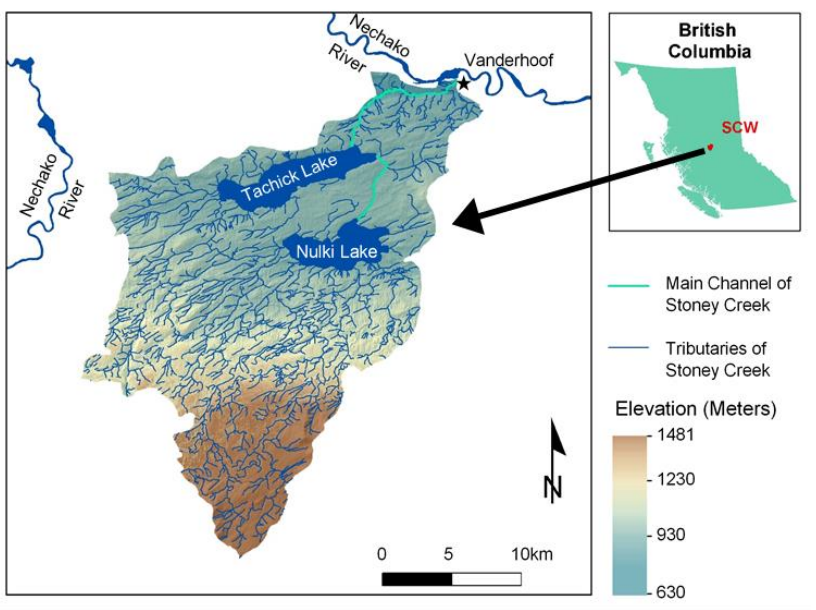

Figure 1. Location and channel network of Stoney Creek Watershed.

In addition to RS and GIS analysis, LULC models are supportive tools for studying the transition among different LULC categories, and models are available to examine the cause and consequence of LULC change (Behera et al., 2012; Hua, 2017). Among them, spatial models can be manipulated using remote sensing data with geographical referenced information, and thus can be effective for predicting the LULC change (Halmy et al., 2015; Urban and Wallin, 2017). Markov Chain (MC) model and other spatially explicit models have been incorporated with RS and GIS technologies for more effective simulation and prediction of LULC change. MC model examines the stochastic nature of LULC change data and forecasts the stability of future land development. It is used by generating a transition probability matrix of LULC change from one period to another (Iacono et al., 2015; Mishra and Rai, 2016; Paul et al., 2018; Azubike et al., 2019).

For a specific study area, each individual model has its limitation to detect all essential LULC change processes. Therefore, it is desirable to combine two or more models to reduce the uncertainty of prediction (Freier et al., 2011; Stabile, 2012; Arekhi and Jafarzadeh, 2014; Qiang and Lam, 2015; Mishra and Rai, 2016). The integration of multilayer perceptron (MLP) neural network model with MC modeling is a recently developed method for quantifying the spatiotemporal change of LULC in a spatially explicit manner. Specifically, the MLP neural network is an innovative algorithm that can automatically generate a large amount of parameter values but requires less data for training (Nasiri et al., 2019). MLP has the capability to model each LULC transition in a study area (Eastman, 2012; Paul, 2013), while MC model is able to predict future LULC change based on transition probability matrixes over a certain period of time. The objective of this study is then to apply a hybrid approach of MLP neural network and MC modeling for geospatial analysis of LULC change and LULC change prediction, through a case study in Stoney Creek Watershed (SCW), British Columbia, Canada. The combined RS and GIS analysis approach is used to process Landsat image data of the study watershed through an OBIA method. The detailed tasks include i) detection of LULC change in SCW from 1986 to 2016, ii) identification of transition potentials of LULC classes driven by different variables, and iii) prediction of LULC scenarios in SCW up to 2026. The results are expected to provide valuable information for environmental conservation and sustainable development planning in the watershed.

\section{Overview of the Study Area}

Stoney Creek Watershed (SCW), with a total drainage area of $496.963 \mathrm{~km}^{2}$, is located to the south-west of Vanderhoof, British Columbia (BC), Canada (Figure 1). Vanderhoof District is not only a significant timber supply area, but also one of the earliest agricultural settlements in BC. Unfortunately, the capacity of agricultural production of SCW has not been fully realized for planned and reserved agricultural lands (RDBN, 2014; Agricultural Land Use Inventory, 2017). The Stoney Creek has a total length of $20.85 \mathrm{~km}$. It meanders through mountainous terrains from its headwater to a relatively flat agriculture and ranching zone, and confluences with the Nechako River near downtown Vanderhoof. Figure 1 shows the main channel of Stoney Creek and its tributaries.

\section{Methodology}

\subsection{Data Selection and Collection}

In this study, several reconnaissance field surveys were conducted for ground truth data collection from 2017 to 2018. The obtained information was used for image classification and accuracy assessment. Information and characteristics of differrent LULC categories were identified based on land survey data and information gained from the stakeholders. In total, $10 \mathrm{LU}-$ LC classes were created and named for the subsequent satellite image analysis, including Agricultural Area (AA), Barren Land (BL), Coniferous Forest (CF), Cut Block (CB), Deciduous Forest (DF), Mixed Forest (MF), Planted/Regrowth Forest (PF), Urban Area (UA), Water (WT) and Dead Pine Trees (DT). A modified version of the Anderson scheme was applied as a reference for describing and identifying LULC classes (Anderson, 1976).

The selection and collection of satellite imagery were considered based on study objectives, availability and quality of satellite images and acquisition time. As a result, three images captured by Landsat 5 Thematic Mapper (TM) level 1 from 1986 and 1999 and Landsat 8 Operational Land Imager (OLI) level 1 from 2016 were selected and downloaded from Earthexplorer and Remotepixel websites for the purpose of capturing 
LULC change within SCW from early 1980s to present (Table 1). For Landsat 5 image data, bands 6 and 7 were excluded. For Landsat 8 data, bands $2 \sim 6$ were selected for the study. In this study, the year 1986 represents the earliest year with available spectral image data of 30-meter resolution. The year 1999 is when significant actions were taken by the BC government such as province-wide aerial overview surveys (Province of $\mathrm{BC}, 2016$ ) after the mountain pine beetle infestation occurred in the central interior region in the late 1990s. The 2016 image represents the current LULC status within SCW. All imagery with less than $5 \%$ or no cloud cover were selected between late July and early August in order to ensure that vegetation categories (including AA, CF, DF and MF) were in good health and maturity. Moreover, by using similar dates from each year can effectively reduce the impact of seasonal variability. In this study, the study area boundary was generated by merging the main Stoney Creek basin and the sub-basins around it based on the distribution range of tributaries. All watershed boundary data was downloaded from the iMapBC website.

Table 1. Description of Selected Satellite Images

\begin{tabular}{lllll}
\hline Year & Date & Landsat & Bands & Resolution $(\mathrm{m})$ \\
\hline 1986 & July 21 & 5 TM Level 1 & $1-5$ & 30 \\
1999 & July 9 & 5 TM Level 1 & $1-5$ & 30 \\
2016 & August 17 & 8 OLI Level 1 & $2-6$ & 30 \\
\hline
\end{tabular}

\subsection{Landsat Image Processing and Analysis}

Processing and analysis of the three satellite images were applied using two main software packages: PCI Geomatica 2017 and Esri ArcGIS 10.5.1. PCI Geomatica 2017 was mostly used to conduct image pre-processing, classification and accuracy assessment. ArcGIS 10.5.1 was used mainly for image post-processing, such as format converting, mapping, and statistical analysis. Figure 2 shows the framework of image processing and analysis.

\subsubsection{Image Pre-Processing}

The SWIR-NIR-Red 'false color' composite provides the user with the highest amount of information and color contrast. This combination has not only been widely used for vegetation studies, but also for timber management and pest infestation (Quinn, 2001). Healthy vegetation is green while soil shows as mauve in this combination. Waterbodies appear in different shades of blue depending on depth and turbidity of water. The Adaptive enhancement, which shows the best enhancement result, was applied for all three Land-sat images (Figure 3).

\subsubsection{Image Classification}

Object Analyst on Geomatica 2017 was utilized to conduct OBIA. There are six steps: segmentation, feature extraction, calculating features, unsupervised classification, rule-based classification and manual editing. To perform OBIA, combinations of different parameters including scale (SC), shape (SP) and compactness $(\mathrm{CP})$ can greatly influence the results of segmentation. The study watershed is mostly covered by forest and agriculture lands and also comprises small features such as built-up areas. Multiple tests in this study showed that the combination with SC: 25 , SP: 0.25 , and CP: 0.5 had the most satisfying segmentation result, as it segmented most of the needed objects with the least disturbances. Performing feature extraction provides attributes of all segments, which are the reference data for image object classification. In Object Analyst, two types of features were computed. The statistical features including minimum, maximum, mean and standard deviation, were computed by the pixels within an object. The geometrical features including compactness, elongation, circularity and rectangularity were computed using the geometric characteristics of objects based on the segment boundary created during segmentation (Geomatica, 2017). All these features were added to the attribute table of each segmentation layer and used as basic band attributes. In order to generate a more accurate classification result, by using statistical features, four new features were calculated, including normalized difference vegetation index (NDVI), TM 2/3 ratio, TM 3/2 ratio and TM 3/4 ratio which can sharply classify live vegetation, croplands and barren lands, forests and croplands, and barren lands and urban area, respectively (NASA 2000; Quinn 2001).

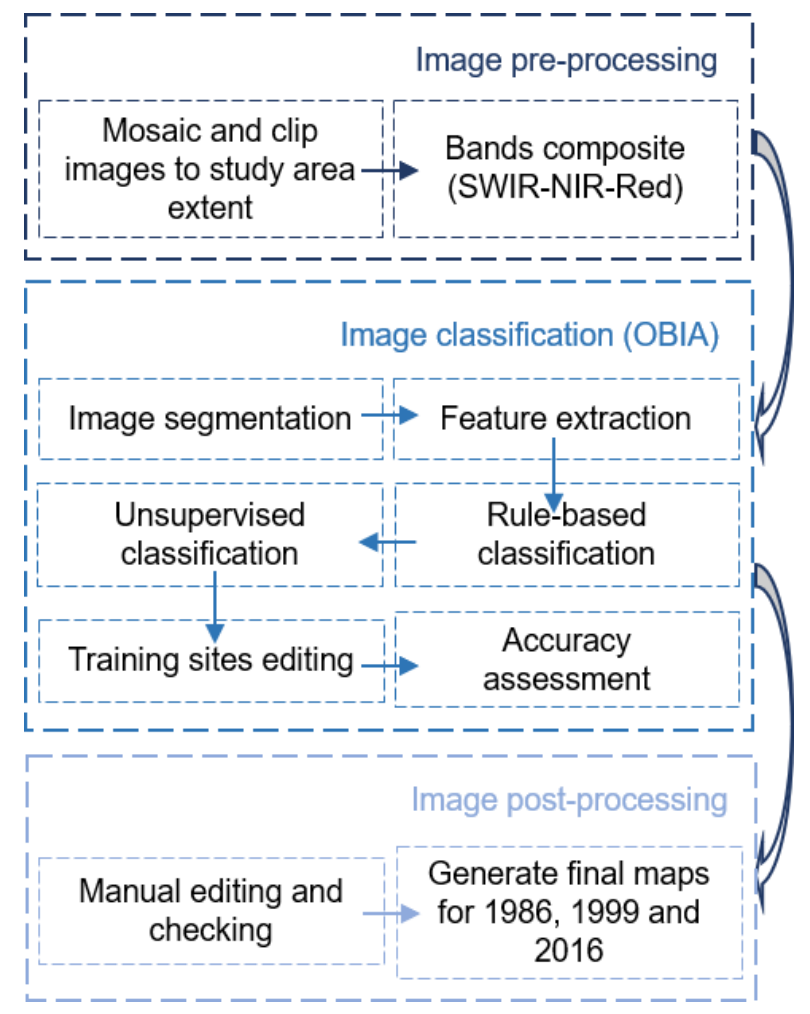

Figure 2. Landsat image processing and analysis framework.

All features for band 3, 4 and 5 (4, 5 and 6 for 2016 image) were selected for unsupervised classification. There were nine classes (no DT class) for images from 1986 and 1999, and ten classes from 2016. In order to get better classification results, clusters were generated with twice as many as the selected LULC classes, and thus 20 clusters were set. To edit and improve 

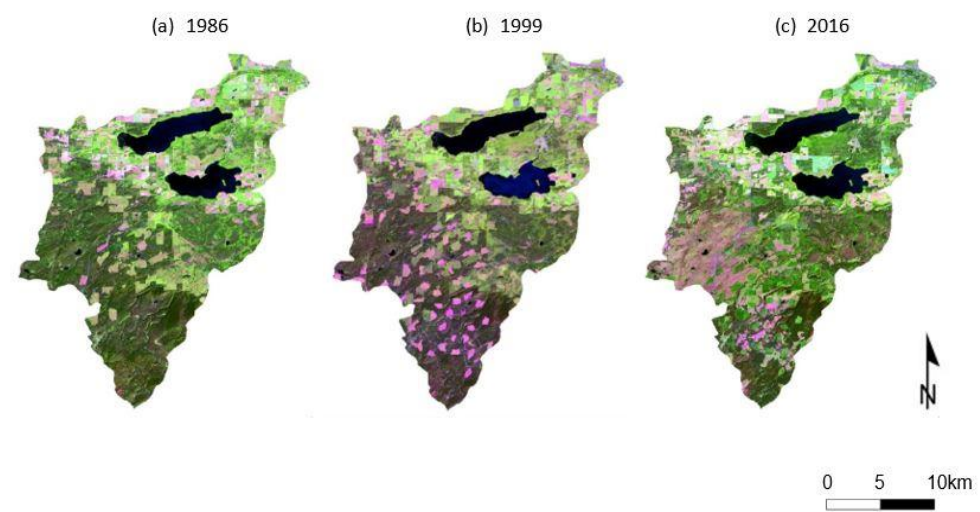

Figure 3. Landsat images in Stoney Creek Watershed for (a) 1986, (b) 1999 (both with 5-4-3 band combination) and (c) 2016 (with 6-5-4 band combination).
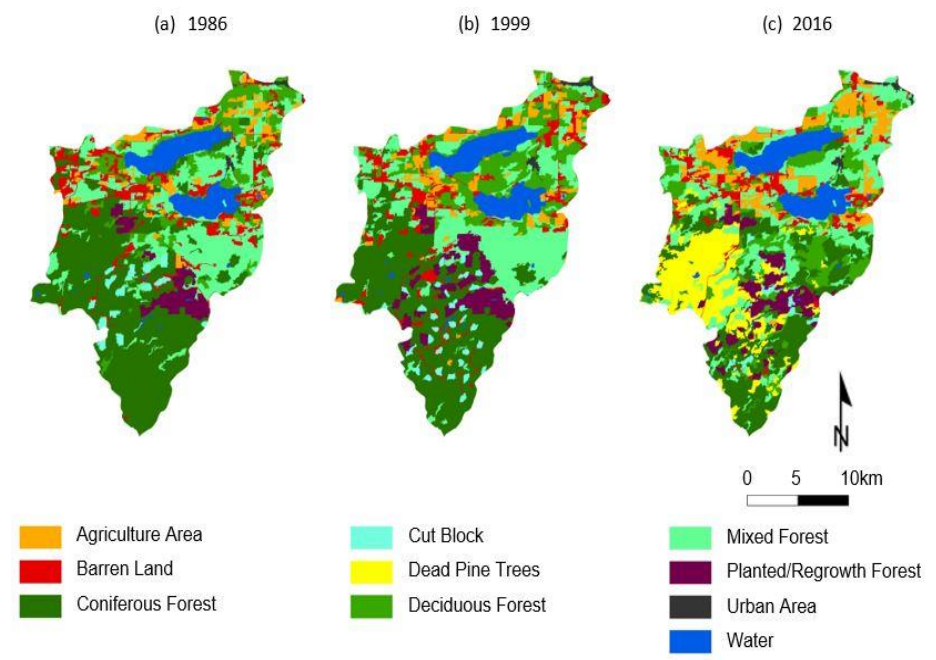

Figure 4. Land use and land cover classification maps of Stoney Creek Watershed in (a) 1986, (b) 1999 and (c) 2016.

classification results, custom classification rules were performed on classified or unclassified segments by assigning or removing them. The rule-based classification tool could simply split a class into subclasses or combine two classes into a new one. An extra step was used to support classification by selecting specific range of a feature. Applicable ranges were picked by adjusting the minimum and maximum values based on testing and ground truth experiences. For example, the cluster with both segments of barren lands and segments of unvegetated croplands could be split by using 'Mean_2/3 Ratio' field as the range field, as this feature is unique for separating barren lands and crop-lands, or by using the 'Rectangle' feature because of the artificial shape of most cropland. Figure 4 shows LULC classification maps of SCW for each year.

\subsubsection{Accuracy Assessment}

Before generating a final classified image, accuracy assessment is usually performed by using a reference map which is field-checked or contains ground truth data for selected sam- pling points (Paul et al., 2018). In this study, because of the lack of reference map and the ground truth data of SCW was only collected from 2017 to 2018, a training field was created for the 2016 image. By comparing unsupervised classified image and training field, three accuracy reports were generated. The classification accuracy of image 2016 could represent the accuracy of images 1986 and 1999 because almost the same procedures, features and rules were applied for classifying the images of all three years. To avoid the subjectivity of manual point selection, ArcGIS points creating tool was used to generate random point layers for accuracy assessment. In total, 200 random points were created to distribute proportionally in relative classes, which means the classes with bigger areas such as 'CF' and 'DF' covered more points than classes with smaller areas. By overlaying the random points layer on the preprocessed satellite image of 2016, segments covering those points were distinguished based on ground truth data and assigned to relative classes.

In the accuracy assessment report, the Kappa coefficient was used to estimate the agreement between a modeled LULC 
Table 2. Introduction of Driver Variables for Transition Potential Modeling

\begin{tabular}{|c|c|}
\hline Driver variable layers & Role \\
\hline $\begin{array}{l}\text { Hazard rating of mountain pine beetle } \\
\text { infestation }\end{array}$ & This driver comprises extent and hazard rating of pine beetle infestation. \\
\hline Distance to major channel network & This driver controls the general hydrology in this watershed. \\
\hline Distance to recommended permanent roads & $\begin{array}{l}\text { This driver responsible for road development, built-up area development, forest clear cutting } \\
\text { etc. }\end{array}$ \\
\hline Digital elevation model (DEM) & $\begin{array}{l}\text { This driver determines the hydrological flow path i.e. overall hydrological process within a } \\
\text { watershed (Paul, 2013). }\end{array}$ \\
\hline Topographic wetness index (TWI) & $\begin{array}{l}\text { TWI defined as } \mathrm{Ln}(\mathrm{A} / \operatorname{tanB})(\text { Sörensen, et al., 2006) where, } \mathrm{A}=\text { local upslope area draining } \\
\text { through a certain point per unit contour length, } \operatorname{tanB}=\text { the local slope. }\end{array}$ \\
\hline $\begin{array}{l}\text { Settlement reserved area and Agriculture } \\
\text { development area }\end{array}$ & $\begin{array}{l}\text { These two can influence future built-up area and croplands development, forest harvesting } \\
\text { etc. }\end{array}$ \\
\hline
\end{tabular}

Table 3. Accuracy Statistic Results for 2016 Image Classification

\begin{tabular}{llll}
\hline $\begin{array}{l}\text { Overall Accuracy: 91.50\% } \\
\text { Overall Kappa Statistic: 0.90 }\end{array}$ & & & \\
\hline Class Name & Producer's Accuracy (\%) & User's Accuracy (\%) & Kappa Statistic \\
\hline Agriculture Area (AA) & 100 & 85.71 & 0.84 \\
Barren Land (BL) & 83.33 & 93.75 & 0.93 \\
Coniferous Forest (CF) & 100 & 88.89 & 0.88 \\
Cut Block (CB) & 92.16 & 95.92 & 0.95 \\
Dead Pine Trees (DT) & 89.47 & 73.91 & 0.71 \\
Deciduous Forest (DF) & 87.5 & 95.46 & 0.95 \\
Mixed Forest (MF) & 88.57 & 91.18 & 0.89 \\
Planted/Regrowth Forest (PF) & 91.67 & 100 & 1 \\
Urban Area (UA) & 100 & 100 & 1 \\
Water (WT) & 100 & 100 & 1 \\
\hline
\end{tabular}

contribution and ground truth (Lillesand et al., 2008). The Kappa coefficient is computed using the following equation (Tadele et al., 2017; Congalton and Green, 2019):

$$
K=\frac{N \sum_{i=1}^{n} X_{i i}-\sum_{i=1}^{n} X_{i+} X_{+i}}{N^{2}-\sum_{i=1}^{n} X_{i+} X_{+i}}
$$

where $N$ is the number of observations; $\mathrm{n}$ is the total number of rows/columns in the error matrix; $X_{i i}$ represents the number of observations in row $i$ and column $i$; and $X_{i+}$ and $X_{+i}$ represents the total number of row $i$ and column $i$, respectively.

Overall accuracy is the ratio between the total number of correct classifications and the total number of classifications. User's accuracy defines the ratio between the number of correct classifications in a category and the total number of classifications in that category, and Producer's accuracy is the ratio between the number correctly identified in reference plots of a given category and the actual number in that reference category.

\subsection{LULC Change Modeling}

\subsubsection{Change Analysis}

Land Change Modeler (LCM), as an integrated application on IDRISI Selva, is employed for LULC change modeling in this study. Figure 5 presents the framework of LULC change modeling. The analysis of historical LULC data was performed through 'Change Analysis' module in LCM and was applied for three sets of time periods: $T_{1}$ (1986 to 1999), $T_{2}$ (1999 to 2016) and $T_{3}$ (1986 to 2016). $T_{1}$ and $T_{2}$ were used for assessing changes (i.e. area gains and losses), and $\mathrm{T}_{3}$ was used for transition potential modeling and change prediction as it represents the time range between the earliest time and the latest time. With the application of six driver variables, each transition that was created by $\mathrm{T}_{3}$ change analysis was modeled as a submodel. Table 2 presents the driver variables, which were selected based on data availability, land use activities and policies as well as the existing references. The variables were converted to layers in IDRISI format and evaluated for their usability.

\subsubsection{Multi-Layer Perceptron (MLP) Neural Network}

Using multi-layer perceptron (MLP) neural network technique, transition potentials were modeled by a back propagation (BP) learning algorithm which can model highly non-linear functions. A typical MLP neural network consists of one input layer, one or more hidden layers and one output layer. Generally, one hidden layer is adequate for most studies (Lin et al., 2011; Eastman, 2012). For running transition submodels, the training process used samples taken from pixels that went through the transition being modeled, or pixels from persistence classes. $50 \%$ of the samples were used for training 
Table 4. Area $\left(\mathrm{km}^{2}\right)$ Statistics of land Use and Land Cover Types for Each Study Year

\begin{tabular}{lllllll}
\hline & \multicolumn{2}{c}{1986} & \multicolumn{2}{c}{1999} & & 2016 \\
\hline LULC Class & Area & $\%$ & Area & $\%$ & Area & $\%$ \\
\hline Agriculture Area (AA) & 24.113 & 4.85 & 30.352 & 6.11 & 47.786 & 9.62 \\
Barren Land (BL) & 45.108 & 9.08 & 40.962 & 8.24 & 32.072 & 6.45 \\
Coniferous Forest (CF) & 191.898 & 38.61 & 153.207 & 30.83 & 94.282 & 18.97 \\
Cut Block (CB) & 9.920 & 2.00 & 11.852 & 2.38 & 4.109 & 0.83 \\
Dead Pine Trees (DT) & 0.000 & 0.00 & 0.000 & 0.00 & 74.339 & 14.96 \\
Deciduous Forest (DF) & 54.290 & 10.92 & 70.465 & 14.18 & 67.306 & 13.54 \\
Mixed Forest (MF) & 111.333 & 22.40 & 112.984 & 22.73 & 106.444 & 21.42 \\
Planted/Regrowth Forest (PF) & 20.257 & 4.08 & 35.288 & 7.10 & 29.585 & 5.95 \\
Urban Area (UA) & 2.037 & 0.41 & 3.188 & 0.64 & 2.835 & 0.57 \\
Water (WT) & 38.006 & 7.65 & 38.664 & 7.78 & 38.205 & 7.69 \\
\hline
\end{tabular}

Table 5. Transition Probability Matrix of Land Use and Land Cover Change from 2016 to 2026

\begin{tabular}{|c|c|c|c|c|c|c|c|c|c|c|}
\hline \multicolumn{11}{|c|}{ Probability of changing to } \\
\hline Given Class & AA & $\mathrm{BL}$ & $\mathrm{CB}$ & $\mathrm{CF}$ & DF & MF & $\mathrm{PF}$ & UA & WT & DT \\
\hline AA & 0.740 & 0.178 & & & 0.056 & 0.027 & & & & \\
\hline BL & 0.203 & 0.399 & & 0.002 & 0.088 & 0.232 & 0.015 & 0.003 & 0.001 & 0.058 \\
\hline $\mathrm{CB}$ & & 0.013 & 0.543 & 0.014 & 0.044 & 0.057 & 0.024 & & 0.001 & 0.306 \\
\hline $\mathrm{CF}$ & & & & 0.000 & & 0.433 & 0.446 & & & 0.121 \\
\hline DF & 0.167 & 0.055 & & 0.011 & 0.303 & 0.459 & & 0.004 & & \\
\hline MF & 0.023 & 0.019 & 0.247 & & 0.293 & 0.408 & 0.006 & 0.002 & 0.002 & \\
\hline $\mathrm{PF}$ & & 0.011 & 0.053 & 0.030 & 0.012 & 0.103 & 0.765 & & & 0.027 \\
\hline UA & & & & 0.000 & & 0.083 & 0.000 & 0.917 & & \\
\hline WT & & 0.002 & 0.002 & & 0.002 & 0.004 & 0.000 & & 0.991 & \\
\hline DT & N/A & N/A & N/A & N/A & N/A & N/A & N/A & N/A & N/A & N/A \\
\hline
\end{tabular}

and the remaining $50 \%$ were used for validation of the transition potential model. MLP in LCM is launched with an automatic training mode, which is capable of monitoring and modifing the start and end learning rates by using the sample training data (Eastman, 2012). Default values are assigned to all the parameters except the number of hidden layer nodes. The default hidden layer nodes were used when the sub-model was run for the first time. More running tests were then performed. If the total accuracy and skill score increase, the value will be doubled, otherwise the last value is selected. Running MLP provided the report with the aggregate accuracy and the skill measure score. The following formula is the measure of model skill (Eastman, 2012):

$S=\frac{(A-E(A))}{(1-E(A))}$

where $E(A)$ is the excepted accuracy, and $A$ is the measured accuracy. The expected accuracy $(E(A))$ is expressed as:

$$
E(A)=\frac{1}{(T+P)}
$$

where $T$ is the number of transitions in the sub-model, and $P$ is the number of persistence classes in the sub-model.

For the purpose of gaining higher modeling accuracy and skill score, it is necessary to remove the variables without power by using the backward stepwise analysis (Eastman, 2012). When running a sub-model with all the variables, each variable was held constant one after another to figure out the one with the least effect on modeling. If the model skill of holding a variable constant was similar with the skill of modeling with all variables, the variable doesn't affect the model significantly and it can be removed.

\subsubsection{Markov Chain (MC) Modeling}

In order to conduct LULC change prediction of SCW, the Markov Chain (MC) modeling was applied with the prediction date as 2026 by using all transition potential sub-models. In this procedure, the MC determines the amount of LULC change using land cover images from the earlier date to later date. It measured how much land is possible to transit from the later date to the prediction date (Eastman, 2012). In the MC method, different categories were applied as the states of a chain. The value at the previous time $t+1\left(X_{t+1}\right)$ only depends on the value at time $\mathrm{t}\left(X_{t}\right)$, and not on the process passing through $X_{t}$. It can be expressed as (Weng, 2002):

$X_{t+1}=f\left(X_{t}\right)$

If the transition probabilities are tabulated in a transition matrix $P, X_{t-l}$ can be expressed as follows (Benito et al., 2010): 
Table 6. Land Use and Land Cover Area Statistics of 2016 and 2026

\begin{tabular}{lllll}
\hline & 2016 & \multicolumn{2}{l}{2026} & Area $\left(\mathrm{km}^{2}\right)$ \\
\hline LULC Class & Area $\left(\mathrm{km}^{2}\right)$ & $\%$ & 59.492 & 11.97 \\
\hline Agriculture Area (AA) & 47.786 & 9.62 & 30.773 & 6.19 \\
Barren Land (BL) & 32.072 & 6.45 & 77.487 & 15.59 \\
Coniferous Forest (CF) & 94.282 & 18.97 & 1.809 & 0.36 \\
Cut Block (CB) & 4.109 & 0.83 & 59.565 & 11.98 \\
Dead Pine Trees (DT) & 67.306 & 13.54 & 93.031 & 18.72 \\
Deciduous Forest (DF) & 106.444 & 21.42 & 30.687 & 6.17 \\
Mixed Forest (MF) & 29.585 & 5.95 & 2.846 & 0.57 \\
Planted/Regrowth Forest (PF) & 2.835 & 0.57 & 38.205 & 7.69 \\
Urban Area (UA) & 38.205 & 7.69 & 103.129 & 20.75 \\
Water (WT) & 74.339 & 14.96 & & \\
\hline
\end{tabular}

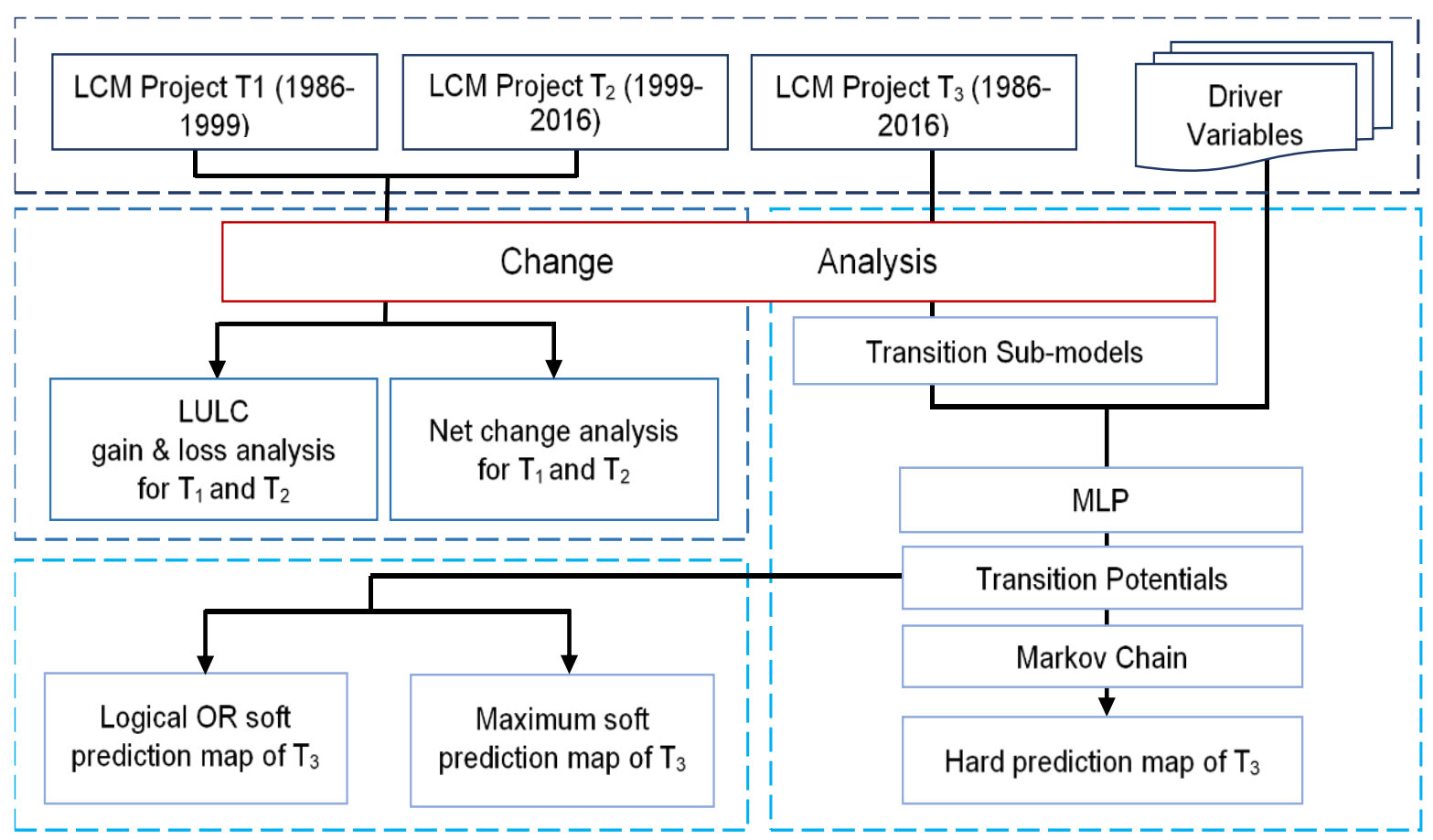

Figure 5. Land use and land cover change modeling framework.

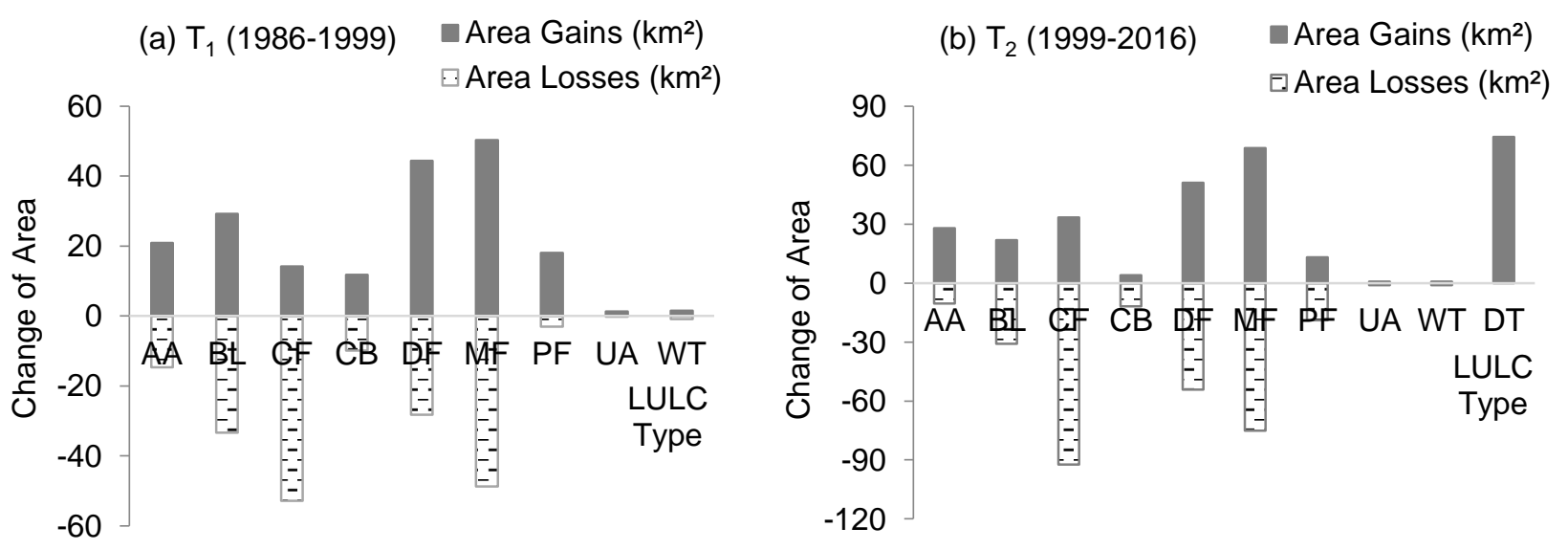

Figure 6. Land gain and loss analysis for period (a) T1 (1986 1999) and (b) T2 (1999 2016). 
$X_{t+1}=X_{t} \cdot P$

The Markov Chain analysis can create a transition probabilities file, which describes the probability of land cover change from one period to another (Houet and Hubert-Moy, 2006; Araya and Cabral, 2010). Two types of soft predictions of the year 2026 were generated based on the present state of the transition potentials for each transition, including $i$ ) the maximum soft output, which shows a maximum transition probability aggregation for all transition potentials, $i$ ) the Logical OR type calculated as $(a+b)-a b)$ (' $a$ ' and ' $b$ ' represent the transition potential of each sub-model) for all transitions included, which could characterize a location with different transitions. Along with the soft output maps of transition probability, a hard prediction LULC map was also created for the year of 2026. A multi-objective land allocation algorithm was then applied to examine all transitions and generate a list of classes with both gain and loss land. While running this allocation procedure, all the changed land of a class was allocated and overlaid to generate the output (Eastman, 2012).

\section{Results and Discussions}

\subsection{Assessment Accuracy}

Table 3 lists the results of producer's accuracy, user's accuracy, overall accuracy and overall Kappa value. In this study, the overall accuracy for image classification of 2016 is $91.50 \%$, while the overall Kappa coefficient is 0.90. Comparing with the PBC method which may inaccurately group pixels with similar spectral reflectance, the integration of OBIA and rule-based classification generated higher classification accuracy, especially for distinguishing between $\mathrm{MF}$ and $\mathrm{CF} / \mathrm{DF}$, and classes with typical features (i.e. UA, WT). Most of the LULC classes have a larger producer's accuracy than overall accuracy except the classes of BL, DF, DT and MF. The lower accuracy for these four classes can be attributed to the limited Landsat image resolution and the lack of comprehensive ground truth data. However, the classification with overall accuracy above $90 \%$ was considered adequate for this study.

\subsection{LULC Change Analysis}

The SCW has an area of $496.963 \mathrm{~km}^{2}$. In 1986, more than $75 \%$ of the watershed was covered by different types of forest, and similarly in 1999, the forest including PF (7.10\%) occupied almost $75 \%$ of the study area (Table 4). Forest lands also covered the majority of the watershed in 2016. However, a new LULC class of DT was added in 2016 that covers $14.96 \%$ of the total area. This LULC class was mostly transferred from CF and partly from MF. Although affected by DT, forest land still comprised almost $60 \%$ of the whole study watershed.

Figure 6 shows the land gain and land loss of different LULC types for both $T_{1}(1986 \sim 1999)$ and $T_{2}(1999 \sim 2016)$. Mature forest land, including CF, DF and MF occupied most of the study watershed from 1986 to 2016 . From 1986 to 1999 , $\mathrm{CF}$ experienced a great negative net change (i.e. more loss than gain) of $38.68 \mathrm{~km}^{2}$, while there was also a negative change for
BL $\left(-4.16 \mathrm{~km}^{2}\right)$. In contrast, other LULC classes had more gain than loss, especially for DF and PF. The obvious changes of forest land may indicate the active forest industry during this period. From 1999 to 2016, the DT class experienced a sharp increase in this area due to the infestation of mountain pine beetles causing CF to lose $58.92 \mathrm{~km}^{2}$ in area. The other classes except AA, also had negative changes. An increasing trend for agricultural area since 1986 was observed, which may be due to the changing policies and activities for agricultural development. The slight net change of UA indicates that there was no significant urban expansion and industrial development. The areas of the town of Vanderhoof and the Saik'uz First Nation Reservation remained stable from 1986 to 2016.

\subsection{Land Change Modeling}

In order to perform transition sub-model simulation, effective driver variable groups for each individual transition sub-model were selected. This was accomplished by utilizing the MLP neural network on LCM. Every driver variable selected for modeling process should be positive to influence the overall accuracy and skill measure. Otherwise, the drivers with no influence were excluded from the group. Running sub-models with ideal driver variable groups generated transition potential maps for individual transitions. Using the transition from CF to DT as an example, Figure 7 shows the change probability from 1986 to 2016.

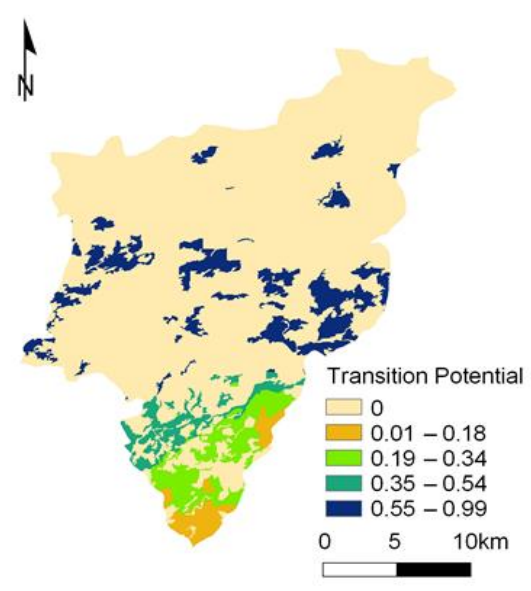

Figure 7. Transition potential map of 'Coniferous Forest' to 'Dead Pine Trees' transition.

The map shows that most areas with transition probabilities of over 0.55 are distributed in the middle part of the watershed. In the 2016 image, the west part of the watershed was mostly covered by DT. The areas near DT are more likely to be affected by mountain pine beetle infestation. Moreover, the more southern the area, the less potential for the transition. Table 5 shows the probability of LULC change and persistence. As shown, classes of UA and WT have high probabilities of remaining as the same land uses (i.e. 0.917 and 0.991), meaning most of these areas can be persistent in 2026. PF (0.765) and AA (0.740) also have high probability of persistence. The pro- 
bability of PF transition to MF is 0.103 . AA has a high probability of remaining as the same land use type, but BL and DF could transfer to AA, with a probability of 0.203 and 0.167 , respectively. These all represent the suitable agricultural management in this area. CB has a probability of 0.543 to change to other LULC types in 2026. This can happen because CB area was planted or regrowth to become other forest lands. Based on the probability matrix, BL, DF and MF have proba-bilities of about $0.3 \sim 0.4$ to remain.

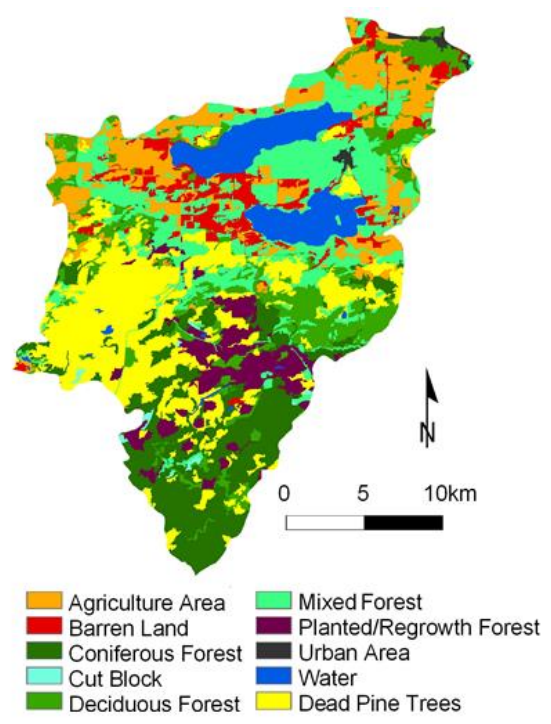

Figure 8. Land use and land cover hard prediction map for 2026.

CF would change to MF and PF, with a probability of 0.433 and 0.446 , respectively. However, further research and more information about mountain pine beetle infestation areas are needed to explain the transitions from $\mathrm{CF}$ to others. The probability of CF changing to DT is 0.121 , and it is the most influential aspect for CF decrease in 2016. As mentioned before, there were no DT type in the earlier date (1986). Therefore, the row for DT in Table 5 is filled as not available (N/A). Figure 8 presents the hard prediction map of 2026.

Table 6 lists the area statistics for both stages (2016 and 2026). DT will gain areas from other classes, but this increasing trend has high uncertainty because of the lack of data for hard prediction. Based on the comparison between 2016 and 2026, AA shows an increasing trend in the next decade referring to a stable and planned agricultural development in this area. Forest land will experience a slight decrease according to the hard prediction data, while the remaining classes have no significant changes.

Similar to the hard prediction, soft prediction is also short of earlier data in the DT class. There was no sub-model for the transition from DT to other LULC types. Therefore, in the soft prediction map, the area of DT in 2016 is persistent. Figure 9 presents two types of soft prediction maps, including a) logical OR soft prediction map which can describe areas with multiple transitions, and b) maximum soft prediction that represents a maximum transition probability aggregation for all transition potentials.

Referring to both soft prediction maps, the middle and north area of the watershed have the highest potential to change. These transitions may be attributed to the agricultural development and forestry activities. In the central north area, the transition probability is variable. Further south, the potential shows a decreasing trend. However, the PF extent has low transition potential, which means a high probability to be persistent. In both soft prediction maps, WT and UA show no probability to change.

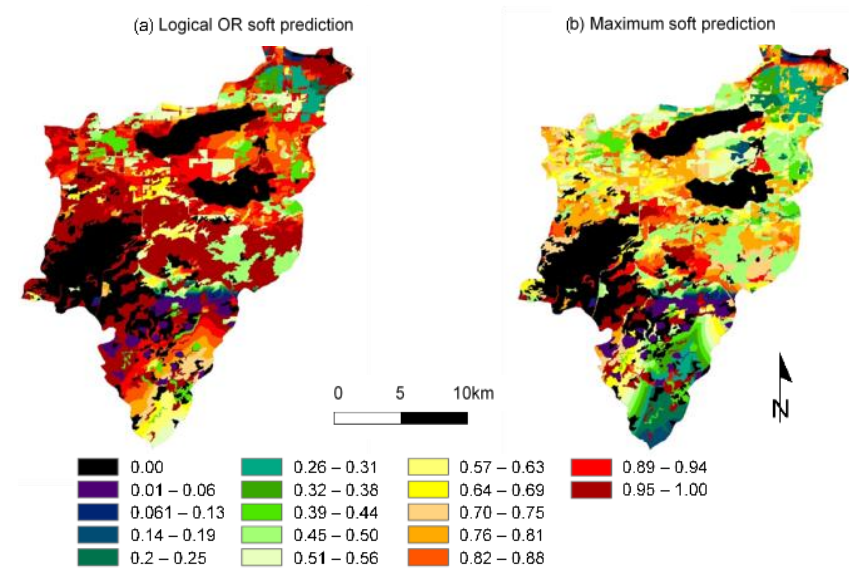

Figure 9. Soft prediction maps for 2026: (a) Logical OR soft prediction, (b) Maximum soft prediction.

\section{Summary}

A Multilayer Perceptron neural network and Markov Chain modeling based geospatial analysis was combined with remote sensing and GIS technologies to conduct LULC change analysis, through a case study in Stoney Creek Watershed (SCW), Canada. Landsat image data were collected. The LULC classification yielded an overall classification accuracy of $91.50 \%$. Based on the LULC change analysis data from 1986 to 2016, transition potentials were modeled by MLP neural network. Markov Chain model was utilized to generate future transition matrixes of 2026, while the matrixes data were applied for hard prediction result generation. Transition potentials were computed together and transferred into soft prediction results, which show the transition probabilities. Based on the results of soft prediction, forestry lands with higher elevations had lower transition probabilities. Areas with the highest potential to change were mainly distributed in the middle and north part of the study watershed, which may refer to agricultural and forestry activities in these areas. If more satellite images for the period of mountain pine beetle infestation can be applied, the modeling outcomes of DT class would be better. Although there was limited availability of high-resolution spatial data, results of the study could provide important information for land use planning and natural resources management within the watershed. The method can also be applied to LULC change analysis in other watershed with similar LULC types. 
Acknowledgments. This research was supported by the National Key Research and Development Plan (2016YFA0601502), and the BC Ministry of Forests, Lands, Natural Resources Operations \& Rural Development.

\section{References}

Agricultural Land Use Inventory. (2017). Vanderhoof and Electoral Area F, Regional District of Bulkley-Nechako. British Columbia Ministry of Agriculture.

Anderson, J.R. (1976). A land use and land cover classification system for use with remote sensor data (Vol. 964). US Government Printing Office. https://doi.org/10.3133/pp964

Araya, Y.H., and Cabral, P. (2010). Analysis and modeling of urban land cover change in Setúbal and Sesimbra, Portugal. Remote Sensing, 2(6), 1549-1563. https://doi.org/10.3390/rs2061549

Arekhi, S., and Jafarzadeh, A.A. (2014). Forecasting areas vulnerable to forest conversion using artificial neural network and GIS (case study: northern Ilam forests, Ilam province, Iran). Arabian Journal of Geosciences, 7(3), 1073-1085. https://doi.org/10.1007/s12517-0 12-0785-1

Azubike, C.S., Kurkalova, L.A., and Mulrooney, T.J. (2019). Modeling Land Use and Land Cover in North Carolina; a Markov Chain Approach. Agricultural and Applied Economics Association.

Behera, M.D., Borate, S.N., Panda, S.N., Behera, P.R., and Roy, P.S. (2012). Modelling and analyzing the watershed dynamics using Cellular Automata (CA)-Markov model-A geo-information based approach. Journal of earth system science, 121(4), 1011-1024. https://doi.org/10.1007/s12040-012-0207-5

Blaschke, T., Hay, G.J., Kelly, M., Lang, S., Hofmann, P., Addink, E., and Tiede, D. (2014). Geographic object-based image analysis towards a new paradigm. ISPRS J. Photogramm. Remote Sens., 87, 180-191. https://doi.org/10.1016/j.isprsjprs.2013.09.014

Butt, A., Shabbir, R., Ahmad, S.S., and Aziz, N. (2015). Land use change mapping and analysis using Remote Sensing and GIS: A case study of Simly watershed, Islamabad, Pakistan. The Egyptian Journal of Remote Sensing and Space Science, 18(2), 251-259. https://doi.org/10.1016/j.ejrs.2015.07.003

Chen, J., Mao, Z., Philpot, B., Li, J., and Pan, D. (2013). Detecting changes in high-resolution satellite coastal imagery using an image object detection approach. International Journal of Remote Sensing, 34(7), 2454-2469. https://doi.org/10.1080/01431161.2012. 743691

Chen L.P., Sun. Y.J., and Saeed, S. (2018). Monitoring and predicting land use and land cover changes using remote sensing and GIS techniques-A case study of a hilly area, Jiangle, China. PloS one, 13(7), e0200493. https://doi.org/10.1371/journal.pone.0200493

Congalton, R.G., and Green, K. (2019). Assessing the accuracy of remotely sensed data: principles and practices. CRC press. https:// doi.org/10.1201/9780429052729

Eastman, J.R. (2012). IDRISI Selva manual and tutorial manual version 17. Worcester (USA): Clark University.

Freier, K.P., Schneider, U.A., and Finckh, M. (2011). Dynamic interactions between vegetation and land use in semi-arid Morocco: Using a Markov process for modeling rangelands under climate change. Agriculture, Ecosystems and Environment, 140(3-4), 462 472.https://doi.org/10.1016/j.agee.2011.01.011

Frohn, R.C., Autrey, B.C., Lane, C.R., and Reif, M. (2011). Segmentation and object-oriented classification of wetlands in a karst Florida landscape using multi-season Landsat-7 ETM+ imagery. International Journal of Remote Sensing, 32(5), 1471-1489. https://doi.org/ $10.1080 / 01431160903559762$

Geomatica. (2017). Geomatica Training Guide: Geomatica II course guide. PCI Geomatics Enterprises, Inc.

Halmy, M.W. A., Gessler, P.E., Hicke, J.A., and Salem, B.B. (2015). Land use/land cover change detection and prediction in the northwestern coastal desert of Egypt using Markov-CA. Applied Geography, 63, 101-112. https://doi.org/10.1016/j.apgeog.2015.06.015

Houet, T., and Hubert-Moy, L. (2006). Modeling and projecting land- use and land-cover changes with Cellular Automaton in considering landscape trajectories. EARSeL eProceedings, 5(1), 63-76.

Hua, A.K. (2017). Application of Ca-Markov model and land use/land cover changes in Malacca River Watershed, Malaysia. Applied Ecology and Environmental Research, 15(4), 605-622. https:// doi.org/10.15666/aeer/1504_605622

Iacono, M., Levinson, D., El-Geneidy, A., and Wasfi, R. (2015). A Markov Chain model of land use change. TeMA Journal of Land Use, Mobility and Environment, 8(3), 263-276. https://doi.org/10. 6092/1970-9870/2985

Islam, K., Jashimuddin, M., Nath, B., and Nath, T.K. (2018a). Land use classification and change detection by using multi-temporal remotely sensed imagery: The case of Chunati wildlife sanctuary, Bangladesh. The Egyptian Journal of Remote Sensing and Space Science, 21(1), 37-47. https://doi.org/10.1016/j.ejrs.2016.12.005

Islam, K., Rahman, M.F., and Jashimuddin, M. (2018b). Modeling land use change using cellular automata and artificial neural network: the case of Chunati Wildlife Sanctuary, Bangladesh. Ecological indicators, 88, 439-453. https://doi.org/10.1016/j.eco lind.20 18.01.047

Lillesand, T.M., Kiefer, R.W., and Chipman, J.W. (2008). Remote sensing and image interpretation (6th ed.). Hoboken, NJ: John Wiley and Sons, Inc.

Lin, Y.P., Chu, H.J., Wu, C.F., and Verburg, P.H. (2011). Predictive ability of logistic regression, auto-logistic regression and neural network models in empirical land-use change modeling-a case study. International Journal of Geographical Information Science, 25(1), 65-87. https://doi.org/10.1080/13658811003752332

Ma, L., Li, M., Ma, X., Cheng, L., Du, P., and Liu, Y. (2017). A review of supervised object-based land-cover image classification. ISPRS Journal of Photogrammetry and Remote Sensing, 130, 277-293. https://doi.org/10.1016/j.isprsjprs.2017.06.001

MacLean, M., Campbell, M., Maynard, D., Ducey, M., and Congalton, R. (2013). Requirements for labelling forest polygons in an objectbased image analysis classification. International Journal of Remote Sensing, 34 (7), 2531-2547. https://doi.org/10.1080/01431161. 2012.747017

Mishra, V.N., and Rai, P.K. (2016). A remote sensing aided multilayer perceptron-Markov chain analysis for land use and land cover change prediction in Patna district (Bihar), India. Arabian Journal of Geosciences, 9(4), 249. https://do i.org/10.1007/s12517-015-21 38-3

NASA Earth Observatory. (2000). Measuring Vegetation (NDVI and EVI), Retrieved from the NASA Earth Observatory website: https://earthobservatory.nasa.gov/features/MeasuringVegetation/m easuring_vegetation_2.php, accessed on September 11, 2018

Nasiri, V., Darvishsefat, A.A., Rafiee, R., Shirvany, A., and Hemat, M.A. (2019). Land use change modeling through an integrated multi-layer perceptron neural network and Markov chain analysis (case study: Arasbaran region, Iran). Journal of Forestry Research, 30(3), 943-957. https://doi.org/10.1007/s11676-018-0659-9

Nguyen, D.T., Iskandar, I., and Ho, S. (2016). Land cover change and the $\mathrm{CO} 2$ stock in the Palembang City, Indonesia: A study using remote sensing, GIS technique and LUMENs. The Egyptian Journal of Remote Sensing and Space Science, 19(2), 313-321. https://doi. org/10.1016/j.ejrs.2016.08.004

Paul, S.S. (2013). Analysis of land use and land cover change in Kiskatinaw River watershed: A remote sensing, GIS and modeling approach (Master Thesis, University of Northern British Columbia, Prince George, BC, Canada). https://doi.org/10.24124/2014/bpgub962

Paul, S.S., Li, J., Wheate, R., and Li, Y. (2018). Application of Object Oriented Image Classification and Markov Chain Modeling for Land Use and Land Cover Change Analysis. Journal of Environmental Informatics, 31(1). https://doi.org/10.3808/jei.201700368

Pervaiz, W., Uddin, V., Khan, S.A., and Khan, J.A. (2016). Satellite- 
based land use mapping: comparative analysis of Landsat- 8 , Advanced Land Imager, and big data Hyperion imagery. Journal of Applied Remote Sensing, 10(2), 026004. https://doi.org/10.1117/1. JRS. 10.026004

Province of BC. (2016). Mountain pine beetle in BC. Retrieved from https://www2.gov.bc.ca/gov/content/industry/forestry/managingour-forest-resources/forest-health/forest-pests/barkbeetles/moun tain-pine-beetle, accessed on September 16, 2016.

Qiang, Y., and Lam, N.S. (2015). Modeling land use and land cover changes in a vulnerable coastal region using artificial neural networks and cellular automata. Environmental monitoring and assessment, 187(3), 57. https://doi.org/10.1007/s10661-015-4298-8

Quinn. J.W. (2001). Band combinations, Retrieved from website: http://web.pdx.edu/ nauna/resources/10_BandCombinations.htm, September 7, 2018.

Rawat, J.S., and Kumar, M. (2015). Monitoring land use/cover change using remote sensing and GIS techniques: A case study of Hawalbagh block, district Almora, Uttarakhand, India. The Egyptian Journal of Remote Sensing and Space Sciences, 18, 77-84. https://doi.org/10. 1016/j.ejrs.2015.02.002

Regional District of Bulkley-Nechako (RDBN) (2014), Vanderhoof and surrounding area profile. Retrieved from website: https://www. rdbn.bc.ca/economicdevelopment/regional-information/regionalprofile, accessed on January 10, 2019.

Rwanga, S.S., and Ndambuki, J.M. (2017). Accuracy assessment of land use/land cover classification using remote sensing and GIS. International Journal of Geosciences, 8(04), 611. https://doi.org/ 10.4236/ijg.2017.84033

Sörensen, R., Zinko, U., and Seibert, J. (2006). On the calculation of the topographic wetness index: evaluation of different methods based on field observations. Hydrology and Earth System Sciences Discussions, 10(1), 101-112. https://doi.org/10.5194/hess-10-101-2 006

Srivastava, P.K., Singh, S.K., Gupta, M., Thakur, J.K., and Mukherjee,
S. (2013). Modeling impact of land use change trajectories on groundwater quality using remote sensing and GIS. Environmental Engineering and Management Journal (EEMJ), 12(12). https://doi. org/10.30638/eemj.2013.287

Stabile, M. (2012). Deconstructing the complexity of land use and cover classification and land change modeling. New South Wales, Australia: Faculty of Agriculture, Food and Natural Resources, The University of Sydney.

Tadele, H., Mekuriaw, A., Selassie, Y.G., and Tsegaye, L. (2017). Land use/land cover factor values and accuracy assessment using a gis and remote sensing in the case of the Quashay watershed in Northwestern Ethiopia. Journal of Natural Resources and Development, 7, 38-44. https://doi.org/10.5027/jnrd.v7i0.05

Toure, S.I., Stow, D.A., Shih, H.C., Weeks, J., and Lopez-Carr, D. (2018). Land cover and land use change analysis using multi-spatial resolution data and object-based image analysis. Remote Sensing of Environment, 210, 259-268. https://doi.org/10.1016/j.rse.2018.03. 023

USGS. (2016). Landsat-Earth observation satellites (ver. 1.1, August 2016): U.S. Geological Survey Fact Sheet 2015-3081, 4 p., http://dx. doi.org/10.3133/fs20153081.

Urban, D.L., and Wallin, D.O. (2017). Introduction to Markov models. In Learning Landscape Ecology (pp. 129-142). Springer, New York, NY. https://doi.org/10.1007/978-1-4939-6374-4_8

Weng, Q. (2002). Land use change analysis in the Zhuajiang Delta of China using satellite remote sensing, GIS and stochastic modeling. Journal of Environmental Management (2002), 64, 273-284. https:// doi.org/10.1006/jema.2001.0509

Zhao, Y., Zhang, K., Fu, Y., and Zhang, H. (2012). Examining landuse/land-cover change in the Lake Dianchi Watershed of the Yunnan-Guizhou Plateau of southwest China with remote sensing and GIS techniques: 1974-2008. International Journal of Environ mental Research and Public Health, 9(11), 3843-3865. https:// doi.org/10.3390/ijerph9113843 